\title{
Genetic and Evolutionary Analysis of Purple Leaf Sheath in Rice
}

Han-shiuan Chin ${ }^{1 \dagger}$, Yong-pei Wu ${ }^{2+}$, Ai-ling Hour ${ }^{3}$, Chwan-yang Hong ${ }^{4}$ and Yann-rong Lin ${ }^{{ }^{*}}$

\begin{abstract}
Background: Anthocyanin accumulates in many plant tissues or organs, in rice for example leading to red, purple red and purple phenotypes for protection from damage by biotic and abiotic stresses and for reproduction. Purple leaf, leaf sheath, stigma, pericarp, and apiculus are common in wild rice and landraces and occasionally found in modern cultivars. No gene directly conferring anthocyanin deposited in a purple leaf sheath has yet been isolated by using natural variants. An $F_{2}$ population derived from ssp. japonica cv. Tainung 72 (TNG72) with purple leaf sheath (PSH) crossed with ssp. indica cv. Taichung Sen 17 (TCS17) with green leaf sheath (GSH) was utilized to isolate a gene conferring leaf sheath color.

Results: By positional cloning, 10-and 3-bp deletions in the R2R3 Myb domain of OsC1 were uncovered in GSH varieties TCS17 and Nipponbare, respectively. Allelic diversity, rather than gene expression levels of OsC1, might be responsible for anthocyanin accumulation. Parsimony-based analysis of genetic diversity in 50 accessions, including cultivars, landraces, and A-genome wild rice, suggests that independent mutation occurred in Asian, African, South American, and Australian species, while O. meridionalis had a divergent sequence. OsC1 was thought of as a domestication related gene, with up to $90 \%$ reduction of genetic diversity in $\mathrm{GSH}$; however, no values from three tests showed significant differences from neutral expectations, implying that OsC1 had not been subjected to recent selection. Haplotype network analysis revealed that species from different continents formed unique haplotypes with no gene flow. Two major groups of haplotypes corresponding to 10-bp deletion and other sequences were formed in Asian rice, including O. rufipogon, O. nivara and O. sativa. Introgressions of OsC1 between subspecies through natural and artificial hybridization were not rare. Because artificial and natural selection imposed admixture on rice germplasm in Taiwan, the genealogy of OsC1 might not be congruent with the current distribution of alleles through lineage diversification.
\end{abstract}

Conclusion: $\mathrm{Os} C 1$ is responsible for purple leaf sheath, and much new information about OsC1 is provided e.g., new alleles, non-domestication syndrome, and incongruence of genealogy with geographic distribution.

Keywords: Genealogy, Genetic Diversity, OsC1, Purple Leaf Sheath

\section{Background}

Plants accumulate diverse pigments in various tissues and organs related to photosynthesis, defense, and reproduction. Anthocyanins, belonging to the flavonoid class of pigment molecules, are important secondary metabolites in rice (Reddy et al. 1995). Anthocyanin accumulation in different tissues is sometimes involved in many physiological functions, such as modulation of hormone responses, protection from damage by ultra-

\footnotetext{
*Correspondence: ylin@ntu.edu.tw

${ }^{\dagger}$ Equal contributors

'Department of Agronomy, National Taiwan University, Taipei, Taiwan

Full list of author information is available at the end of the article
}

violet radiation, and defense responses to biotic and abiotic stresses (Reddy et al. 1994; Chalker-Scott 1999; Ithal and Reddy 2004). Purple stigma and apiculus attract insects for pollination and animals for seed dispersal, respectively. Different degrees of purple color are commonly found in the root, leaf sheath, leaf blade, stigma, and apiculus of wild rice species and landraces and occasionally seen in cultivars. Allelic diversity of genes conferring purple pigmentation is maintained in natural germplasm.

Anthocyanin metabolism is regulated by genes and influenced by environmental factors such as $\mathrm{pH}$, ultraviolet radiation and temperature, which have been well

\section{至 Springer}


studied in maize, Petunia, Arabidopsis and other model plants (Dooner et al. 1991; Brenda 2001; Koes et al. 2005). In addition to the genes encoding enzymes participating in the anthocyanin synthesis pathway, several regulatory genes including members of the $C 1, P l, B$ and $R$ gene families in maize have been identified and their functions elucidated. $\mathrm{C} 1$ and $\mathrm{Pl}$ proteins containing $\mathrm{Myb}$ DNA binding domains regulate downstream genes of the flavonoid synthesis pathway; while $\mathrm{B}$ and $\mathrm{R}$ proteins containing a basic helix-loop-helix (bHLH) domain are transcriptional activators (Chandler et al. 1989). Based on sequence similarity, $O s C 1, O s B 1$ and $O s B 2$, which are homologous to maize $C 1$ and $B$, were isolated from rice (Reddy et al. 1998; Sakamoto et al. 2001). The N-terminal and bHLH domains of OsB1 and OsB2 take advantage of protein-protein interaction with $\mathrm{OsC} 1$ that have an $\mathrm{R} 2 \mathrm{R} 3$ Myb domain, and these proteins regulate directly the downstream genes of the flavonoid synthesis pathway (Sakamoto et al. 2001; Koes et al. 2005).

Asian rice, Oryza sativa, was domesticated from wild species, O. rufipogon, an estimated 10,000 years ago. The domestication syndromes are considered to include aspects of grain color, grain size, yield, and other desirable agronomic traits. Domestication-related genes have been classified in terms of crop domestication, improvement and diversification (Kovach et al. 2007; Larson et al. 2014). Shattering genes, sh 4 and $q S H 1$, were deliberately modified to influence harvest efficiency as recently as the past 100 years, contributing directly to rice domestication (Zhang et al. 2009). Another key domesticationrelated gene, $s d-1$, resulting in semi-dwarf stature, was a key element of the 'Green Revolution' in the 1960s in Asia by virtue of dramatically increasing grain yield (Asano et al. 2007). The purple apiculus trait which is common in wild rice but rare in cultivars is controlled by a regulatory gene, $\mathrm{OsC1}$. Allelic diversity of $\mathrm{OsC1}$ revealed signatures of selection in cultivated Asian rice but not in indigenous improved rice varieties in North India (Saitoh et al. 2004; Choudhury et al. 2014). Nevertheless, some crop improvement traits are regional preferences, such as grain texture and flavor regulated by waxy and $B A D H 2$ which harbor allelic diversity in different landraces and cultivars (Olsen and Purugganan 2002; Kovach et al. 2009).

In rice, purple leaf sheath (PSH) as well as purple apiculus and stigma is common in wild species and landraces; however, green leaf sheath (GSH) is prevalent in modern cultivars. One or two major QTLs were suggested to confer leaf sheath color, and two QTLs mapped on chromosomes 1 and 6 could explain more than $50 \%$ of phenotypic variation (Hadagal et al. 1980; Yue et al. 2006). A purple leaf sheath gene, PSH1 (t), was narrowed down to an interval of $23.5 \mathrm{~kb}$ on chromosome 1 encompassing 6 candidate genes after high resolution of linkage mapping. No gene directly conferring PSH has yet been isolated by using natural variants.

In this study, an $F_{2}$ segregating population of ssp. japonica cv. Tainung 72 (TNG72) with purple leaf sheath $\times$ ssp. indica cv. Taichung Sen 17 (TCS17) with green leaf sheath was utilized to isolate a gene conferring leaf sheath color by positional cloning. Four accessions with various levels of anthocyanin accumulation in the leaf sheath were used to investigate the relationship between gene expression and anthocyanin content. Analyses of haplotype and nucleotide diversity based on 50 rice accessions which included improved cultivars, landraces, and wild species were conducted to reveal if the gene has been responsive to artificial selection and the associated geographic distribution of its alleles.

\section{Result}

Accumulation of Anthocyanins in Tissues of TNG72 and TCS17 at Various Growth Stages

TNG72 possessed purple coleoptile, leaf sheath, apiculus, and stigma, and the degrees of purple color varied at different growth stages (Fig. 1a-e). The leaf sheath of TNG72 was green at the 4-leaf stage but gradually turned purple until the active tillering stage, remaining purple until maturity. TNG72 accumulated various amounts of anthocyanin with different localization in rice tissues. However, TCS17 remained green for the entire life cycle, representing the most common phenotype of cultivated rice (Fig. 1a-e).

Both TNG72 and TCS17 possess green leaf blades for their entire life. The anthocyanin contents of TNG72 and TCS17 leaf blades did not differ significantly although TNG72 was somewhat higher at both seedling and tillering stages (Fig. 1f) and may have already had anthocyanins at a level too low to be discerned visually. On the other hand, TNG72 had significantly higher $(p<$ $0.05)$ anthocyanin content in leaf sheaths than TCS17. Leaf sheath anthocyanin contents were estimated as $0.06 \mu \mathrm{mol} / \mathrm{g}$ and $0.01 \mu \mathrm{mol} / \mathrm{g}$ at the 4-leaf seedling stage; and $1.16 \mu \mathrm{mol} / \mathrm{g}$ and $0.05 \mu \mathrm{mol} / \mathrm{g}$ at active tillering for TNG72 and TCS17, respectively (Fig. 1f).

\section{Isolation of the Gene Conferring the Leaf Sheath Color}

The $\mathrm{F}_{2}$ population of TNG72 $\times$ TCS17 was used to identify the gene conferring leaf sheath color by positional cloning. A total of $632 \mathrm{~F}_{2}$ progenies included 473 and 159 individuals exhibited PSH and GSH, respectively. The segregation ratio of 2.9:1 (PSH: GSH) followed single-gene Mendelian inheritance, indicating that GSH was recessive. A randomly selected $46 \mathrm{~F}_{2}$ plants with green leaf sheath were genotyped with 117 polymorphic markers distributed over the 12 rice chromosomes, permitting the gene to be coarsely mapped between CH0639 and RM276 on the short arm of chromosome 6 

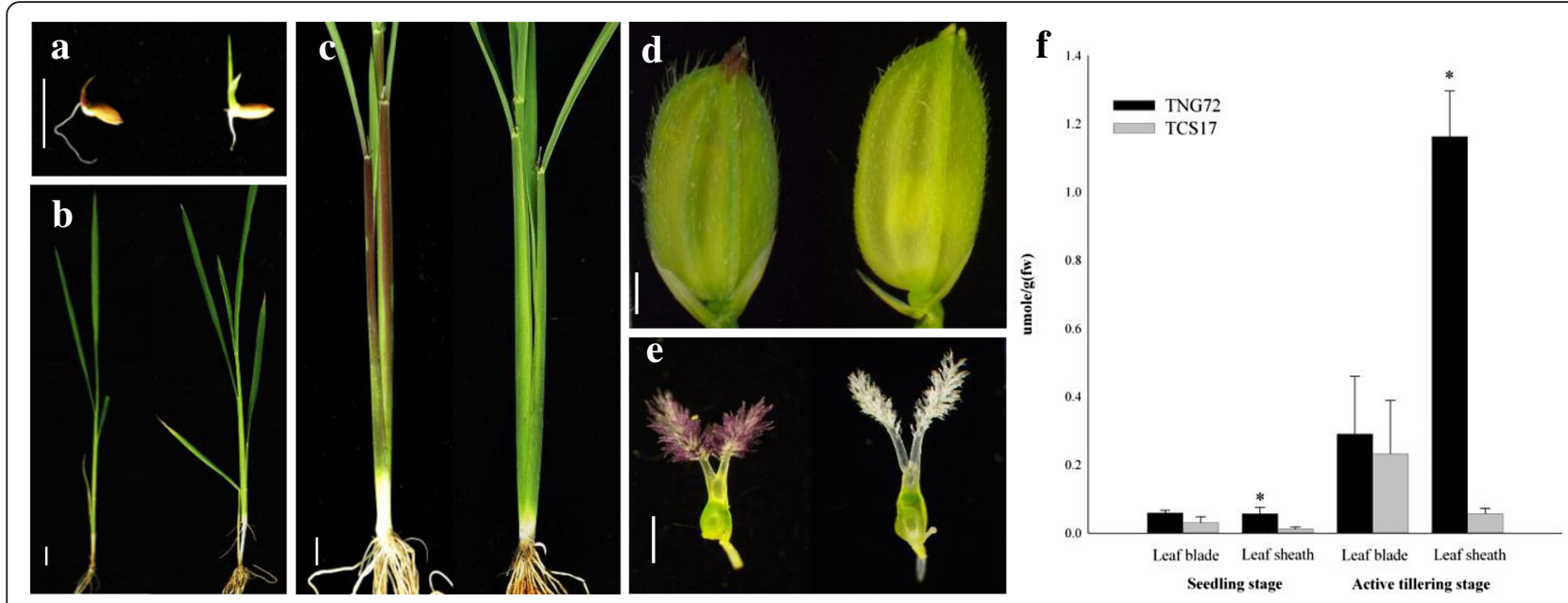

Fig. 1 Phenotypes of Tainung 72 (TNG72) and Taichung Sen 17 (TCS17) for different tissues and growth stages. All of the figures are established that left is TNG72 and right is TCS17. Plants at (a) coleoptile, (b) 4-leaf stage, (c) active tillering stage, (d) caryopsis and (e) stigma at flowering time. Bar size is (a) $1 \mathrm{~cm}$; (b), (c), and (d) $5 \mathrm{~cm}$; (e) $1 \mathrm{~mm}$. (f) Estimated anthocyanin contents in leaf sheath and blade at seedling and active tillering stages. ${ }^{*} p<0.05$ using paired t-test

(Fig. 2). An additional $113 \mathrm{~F}_{2}$ plants with $\mathrm{GSH}$ were genotyped with 3 more markers for fine mapping. The target interval was $162.04 \mathrm{~kb}$, between $\mathrm{CH} 0611$ and RM253 encompassed by 3 BACs, OsJNBa00161019, OsJNBb0015B15, and P0529B09. By retrieving the Rice Genome Annotation Project database (RGAP, http:// rice.plantbiology.msu.edu), it was found that one of 25 candidate genes, Os06g10350, annotated as a MYB family transcription factor, was the most likely gene. Os06g10350 corresponded to Os06g0205100, annotated as transcription factor MYB6, O. sativa $\mathrm{C} 1$, a rice homo$\log$ of maize $\mathrm{C} 1$ in the Rice Annotation Project database (RAP, http://rapdb.dna.affrc.go.jp/).

TNG72 with PSH possessed a full-length OsC1 DNA sequence encoding 272 amino acids. TCS17 with GSH had a 10-bp deletion in the R3 Myb domain, which was considered a core domain in exon 3 of OsC1. The 10-bp deletion resulted in a frame shift, translating only 207 amino acids and leading to a premature stop codon. In the reference genome sequence of Nipponbare on RGAP, a 3-bp deletion of part of the R3 Myb domain in exon 2 was noted, for which Nipponbare has GSH. The results revealed that an aberrant R3 Myb domain of anthocyanin regulatory $\mathrm{C} 1$ protein caused a deficit in anthocyanin synthesis in TCS17 and Nipponbare.

\section{Natural Variation in Leaf Sheath Colors}

Purple leaf sheath is a common phenotype in wild rice. In this study, among the 7 wild rices utilized in the Oryza Map Alignment Project (OMAP), all except $O$. nivara (103813) exhibit PHS. One accession of O. rufipogon collected from Taiwan also has purple leaf sheath. Nevertheless, the majority of cultivated rice has GSH.
Among the 43 accessions of $O$. sativa selected to study genetic diversity of $\mathrm{OsC1}, 17$ indica and 12 japonica accessions possess green leaf sheath, while 5 indica and 9 japonica accessions possess purple leaf sheath (Table 1 ). Because of the intention to study allelic variation of $\mathrm{OsC1}$, more japonica landraces exhibiting various degrees of purple color on the leaf sheath were included.

Various degrees of purple color were obvious among different rice accessions. Fourteen accessions, including 2 cultivars and 3 landraces of indica rice, and 1 cultivar and 8 landraces of japonica rice, ranged from light to dark purple. According to the RHS (Royal Horticultural Society) Color Charts 5th Edition, the leaf sheath of 6, 3, 3 , and 2 accessions showed tyran rose, pansy purple, red purple, and blackish purple, respectively (Fig. 3a). The estimated anthocyanin content of the GSH cultivar, Tainung 67 (TNG67), was $0.03 \mu \mathrm{mol} / \mathrm{g}$. The anthocyanin contents of $14 \mathrm{PSH}$ ranged from 1.04-42.77 $\mu \mathrm{mol} / \mathrm{g}$, for which Chuan4 with tyran rose had the least while Kun Shan Wu Siang Keng (KSWSK) with blackish purple had the most. The 14 accessions could be divided into 7 groups with significant differences (LSD, $p \leq 0.05$ ), in which color degrees were in proportion to anthocyanin contents (Fig. 3a).

One japonica GSH accession, TNG67, and 3 japonica PSH accessions, TNG72, Shang Chi Tsao Tao (SCTT) and KSWSK, exhibiting different degrees of purple color in the leaf sheath were used to evaluate gene expression of OsC1. At the active tillering stage, the estimated anthocyanin contents of these four accessions were significantly different (Fig. 3a). The relative gene expression of 3 accessions with purple leaf sheath was 18-fold higher than TNG67, a highly significant difference (Fig. 3b). 


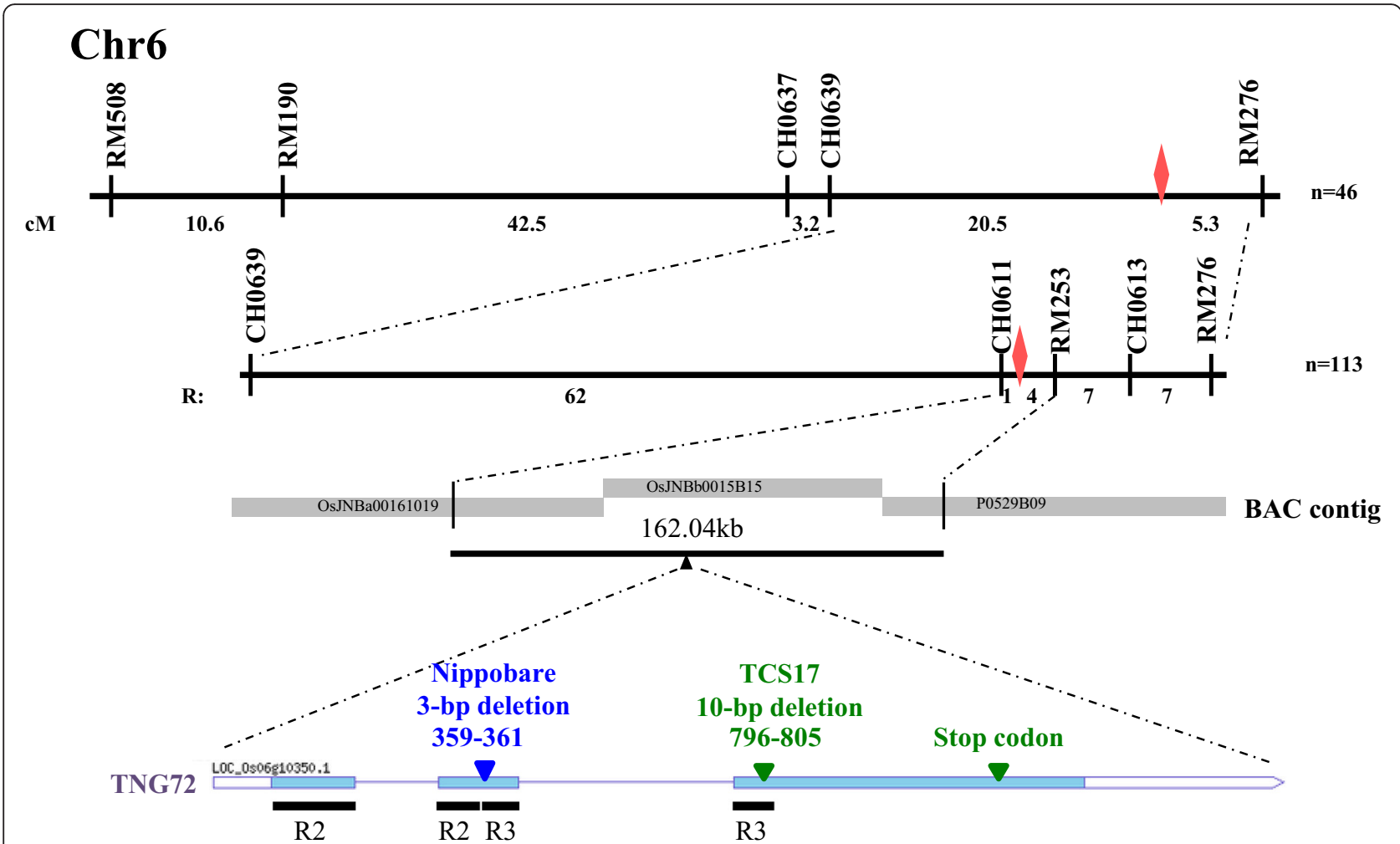

Fig. 2 Isolation and sequence analysis of the gene conferring responsible for purple leaf sheath. Coarse mapping of the purple leaf sheath gene between $\mathrm{CH} 0639$ and RM276 on chromosome 6. Fine mapping narrows down this region to $160.04 \mathrm{~kb}$ between $\mathrm{CH} 0611$ and RM253. The LOC_06g10350 locus was annotated as MYB family transcription factor by RGAP and corresponded to Os06g0205100 annotated as transcription factor MYB6 and O. sativa C1, and rice homolog of maize C1 by RAP. Sequence analysis of 3 cultivars, Tainung 72 (TNG72), Nipponbare and Taichung Sen 17 (TCS17). TNG72 has complete sequences translated into 272 amino acids. Nipponbare has 3-bp deletion in the second exon of OsC1, and is translated into 271 amino acids. TNG17 has 10-bp deletion in the third exon of OsC1, and is translated into 207 amino acids. The black lines are conserved domains of OsC1, R2R3 Myb domain. The triangles indicate sites of variation

Nevertheless, there were no significant differences among the $3 \mathrm{PSH}$ accessions by using LSD analysis.

\section{Nucleotide Diversity and Haplotype Network of OsC1}

Fifty accessions collected from 9 countries, mainly from Taiwan, were subjected to analysis of OsC1 nucleotide variation and its haplotype network (Table 1). These 50 accessions could be classified into 5 groups, with Groups I-IV sharing high similarity of DNA sequence while Group V including 6 A-genome wild rices exhibited more allelic diversity (Fig. 4). For Group I, all 14 accessions shared high sequence similarity with TNG72. The majority of Group I belonged to ssp. japonica except 1 indica cultivar, Tainung Sen 20. The leaf sheaths of three accessions were tyran rose or pansy purple. Nevertheless, 8 accessions had GSH although OsC1 function was predicted to be normal. Group II, consisting of 4 indica and 2 japonica accessions, shared the same sequence as SCTT. There were 5 SNPs that differentiated the group from the OsC1 sequence of TNG72, and one SNP located at position 1,192 bp in exon 3 conferred nonsynonymous substitution of valine to alanine.
All 6 accessions had PSH with colors of tyran rose, pansy purple, and red purple. Group III, including 5 accessions, had one SNP in common at position $918 \mathrm{bp}$ on exon 3, resulting in nonsynonymous substitution from proline to glutamine. All 5 accessions shared high sequence similarity to KSWSK. Three accessions, including 2 japonica landraces and O. rufipogon Taiwan Type 1, had blackish purple leaf sheath; while the other 2 had green leaf sheath. Group IV, consisting of 16 indica and 3 japonica accessions, had the same 10-bp deletion at position 796-805 bp as TCS17, causing frameshift mutation. All 19 accessions had green leaf sheath. Group V consisted of all A-genome wild rices except O. rufipogon Taiwan Type 1. The nucleotide sequences of the 6 wild rices were highly diverse, especially that of $O$. meridionalis. Five of the 6 wild rices had PSH with various degrees of purple color but O. nivara (103813) had GSH (Fig. 4).

Haplotype network analysis of $\mathrm{OsC1}$ gene sequences of these 50 accessions revealed 17 haplotypes with four major distinct groups comprised of Asian, African, Australian, and South American rice, in agreement with genealogical lineages. The 43 accessions of Asian cultivated 
Table 1 A total of 50 accessions for nucleotide diversity analysis

\begin{tabular}{|c|c|c|c|}
\hline Taxon & Accession & Origin & $\begin{array}{l}\text { Color of } \\
\text { leaf she }\end{array}$ \\
\hline \multicolumn{4}{|c|}{ O. sativa ssp. indica } \\
\hline \multirow[t]{9}{*}{ cultivars } & Tainung Sen 20 & Taiwan & Purple \\
\hline & Jianungyu 892229 & Taiwan & Green \\
\hline & Jianungyu 892234 & Taiwan & Green \\
\hline & Taichung Sen 17 & Taiwan & Green \\
\hline & Taichung Native 1 & Taiwan & Green \\
\hline & IR 13525-118-3-2-2-2 & $\begin{array}{l}\text { The } \\
\text { Philippines }\end{array}$ & Purple \\
\hline & IR64 & $\begin{array}{l}\text { The } \\
\text { Philippines }\end{array}$ & Green \\
\hline & Hua Keng Sen 7 & China & Green \\
\hline & Hu Han 15 & China & Green \\
\hline \multirow[t]{13}{*}{ landrace } & Cheng Ching Yu & Taiwan & Green \\
\hline & Cheng Wu Chan & Taiwan & Green \\
\hline & Chu Tzu & Taiwan & Green \\
\hline & Dee Geo Woo Gen & Taiwan & Green \\
\hline & Hua Lou & Taiwan & Green \\
\hline & Midon & Taiwan & Green \\
\hline & Jinya-149 & Taiwan & Purple \\
\hline & G 124 & India & Purple \\
\hline & Shui Pai Tiao & China & Purple \\
\hline & Fu P'I Sen & China & Green \\
\hline & Hsia Men Chung & China & Green \\
\hline & Liu Shih Jih Tsao & China & Green \\
\hline & Yin Yu Tzu & China & Green \\
\hline \multicolumn{4}{|c|}{ O. sativa ssp. japonica } \\
\hline \multirow[t]{8}{*}{ cultivars } & Tainung 72 & Taiwan & Purple \\
\hline & Taichung 65 & Taiwan & Green \\
\hline & Tainung 67 & Taiwan & Green \\
\hline & Shinriki & Japan & Green \\
\hline & Asamurasaki & Japan & Purple \\
\hline & Kameji & Japan & Green \\
\hline & Nipponbare & Japan & Green \\
\hline & Nohrin 1 & Japan & Green \\
\hline \multirow[t]{9}{*}{ landrace } & Chuan4 & Taiwan & Purple \\
\hline & $\begin{array}{l}\text { Kun Shan } \\
\text { Wu Siang Keng }\end{array}$ & Taiwan & Purple \\
\hline & Tongsisai & Taiwan & Purple \\
\hline & Warisanmochi 2 & Taiwan & Purple \\
\hline & Baridon & Taiwan & Green \\
\hline & Chien Tzu Chu & Taiwan & Green \\
\hline & Ch'ih K'o & Taiwan & Green \\
\hline & Nobohai & Taiwan & Green \\
\hline & Munagurusu & Taiwan & Green \\
\hline
\end{tabular}

Table 1 A total of 50 accessions for nucleotide diversity analysis (Continued)

\begin{tabular}{llll}
\hline & Ssall-Bye & Taiwan & Purple \\
& 4233 & China & Purple \\
Shang Chi & China & Purple \\
& Yen No & China & Green \\
O. barthii & 10412 & Cameroon & Purple \\
O. glaberrima & 96717 & Senegal & Purple \\
O. glumaepatula & 105668 & Brazil & Purple \\
O. meridionalis & 105300 & Australia & Purple \\
O. nivara & 103813 & China & Green \\
O. nivara & 104683 & India & Purple \\
O. rufipogon & Taiwan type 1 & Taiwan & Purple \\
\hline
\end{tabular}

rice and their wild progenitors, 2 accessions of $O$. nivara and 1 accession of $O$. rufipogon, formed 13 interconnected haplotypes. The African cultivated species O. glaberrima and its wild progenitor, O. barthii, had different haplotypes, H14 and H15; however, these two haplotypes were connected. O. meridonalis (from Australia) and O. glumaepatula (South America) each formed independent unique haplotypes, $\mathrm{H} 16$ and $\mathrm{H} 17$, respectively (Fig. 5).

$\mathrm{OsC1}$ in the $7 \mathrm{~A}$-genome wild rices, as expected, exhibited rich nucleotide diversity, especially in O. meridonalis, as revealed by haplotype number $(\mathrm{H})$, haplotype diversity $\left(\mathrm{H}_{\mathrm{d}}\right)$, polymorphic sites $(\mathrm{S})$, pairwise nucleotide difference $\left(\pi_{\mathrm{T}}, \pi_{\mathrm{sil}}\right)$, and Watterson's estimators of $\theta_{\mathrm{T}}$ and $\theta_{\text {sil }}$ (Table 2). Nucleotide diversity of $O s C 1$ in cultivated $O$. sativa was apparently reduced. In general, more genetic variation was detected in indica than japonica rice. Greater sequence polymorphism was noted in PSH than GSH accessions in both indica and japonica rice despite characterizing more GSH accessions. Up to $90 \%$ reduction of genetic diversity in GSH was revealed by the average number of pairwise nucleotide differences per site based on the total number of polymorphic sites $\left(\pi_{T}\right)$; however, less reduction in silent sites was indicated by $\pi_{\text {sil }}$ and $\theta_{\text {sil }}$ (Table 2).

Tajima's D and Fu and Li's D \& F were applied to test whether $\mathrm{OsC} 1$ deviated from the neutral expectation of heterozygosity, but no values were statistically significant, indicating no evidence of strong selection (Table 3). The overall values were negative in $O$. sativa and the other A-genome species. Positive values, implying balancing selection, were noted in indica PSH accessions but not in japonica PSH accessions. Negative selection or purifying selection acting on $\mathrm{OsC1}$ could not be ruled out in indica GSH accessions $(0.01 \leq p \leq 0.05)$. 


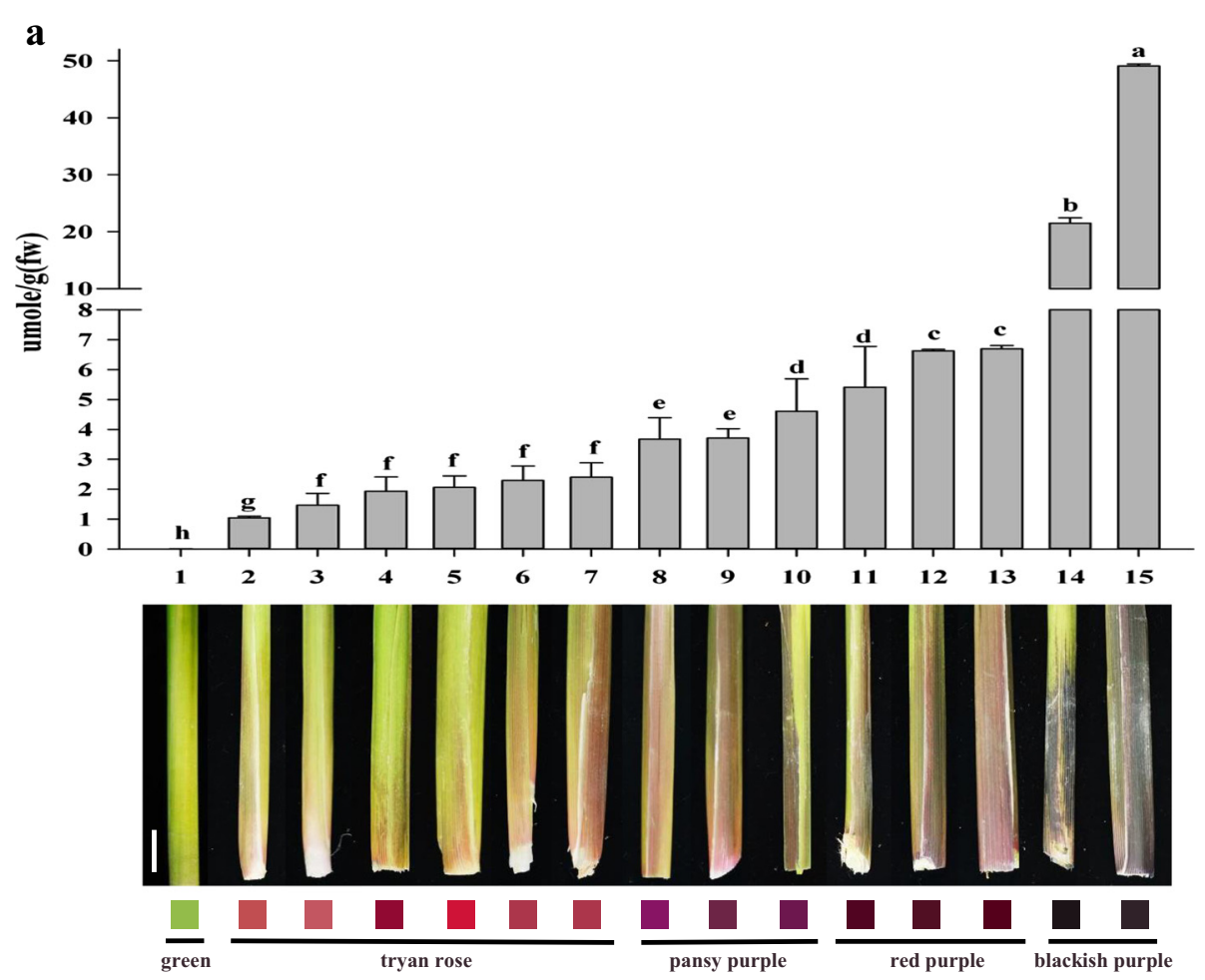

b

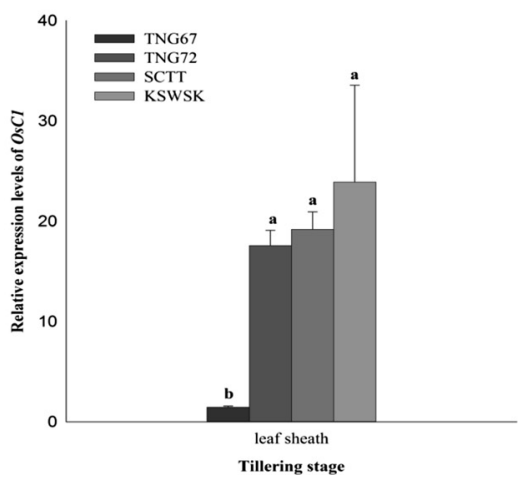

Fig. 3 Anthocyanin accumulation and gene expression of $\mathrm{OsCl}$ in the leaf sheath. (a) Phenotypes and anthocyanin contents of 1 green leaf sheath (GSH) accession and 14 purple leaf sheath (PSH) accessions with various degrees of purple. The 15 accessions are Tainung 67 (TNG67) (1), Chuan4 (2), G124 (3), Warisanmochi2 (4), Shui Pai Tiao (5), Tonsisai (6), IR13525-118-3-2-2-2 (7), 42338 (8), Jinya-149 (9), Tainung 72 (TNG72) (10), Ssall-Bye (11), Tainung Sen 20 (12), Shang Chi Tsao Tao (SCTT) (13), Asamurasaki (14), and Kun Shan Wu Siang Keng (KSWSK) (15). Leaf sheath phenotypes are characterized according to the RHS (Royal Horticultural Society, 5th edition) Color Charts. (b) Gene expression of OsC1 in the leaf sheath of 4 cultivars at tillering. Cultivars TNG67, TNG72, SCTT and KSWSK, exhibiting diverse degrees of purple color, were selected to evaluate gene expression by real-time PCR. Letters indicate differences at significance level $p<0.05$ by using LSD analysis

Asian rice could be divided two major subgroups, with Group A including two haplotypes (H1, H2) and Group B including 11 haplotypes (H3-H13) (Fig. 5). All accessions of Group A exhibited GSH, and haplotype H1 containing 15 indica accessions and 3 japonica landraces all had the same 10-bp deletion. One indica landrace, Cheng Ching $\mathrm{Yu}$, has an additional single nucleotide substitution, resulting in another haplotype, H2 (Figs. 4 and 5). Group B contained 27 accessions, $11 \mathrm{GSH}$ and
16 PSH with various degrees of purple. According to the haplotype network, 3 major clusters, B1-B3, could be resolved within Group B. The 12 accessions of Cluster B1 shared the same sequence with PSH TNG72 but 7 were phenotypically GSH. All 6 accessions of Cluster B2 (4 indica and 2 japonica landraces), expressed pansy purple and red leaf sheath, similar to SCTT. Cluster B3 had 2 GSH and 3 PSH accessions sharing high sequence similarity with KSWSK. Interestingly, O. rufipogon (Taiwan 


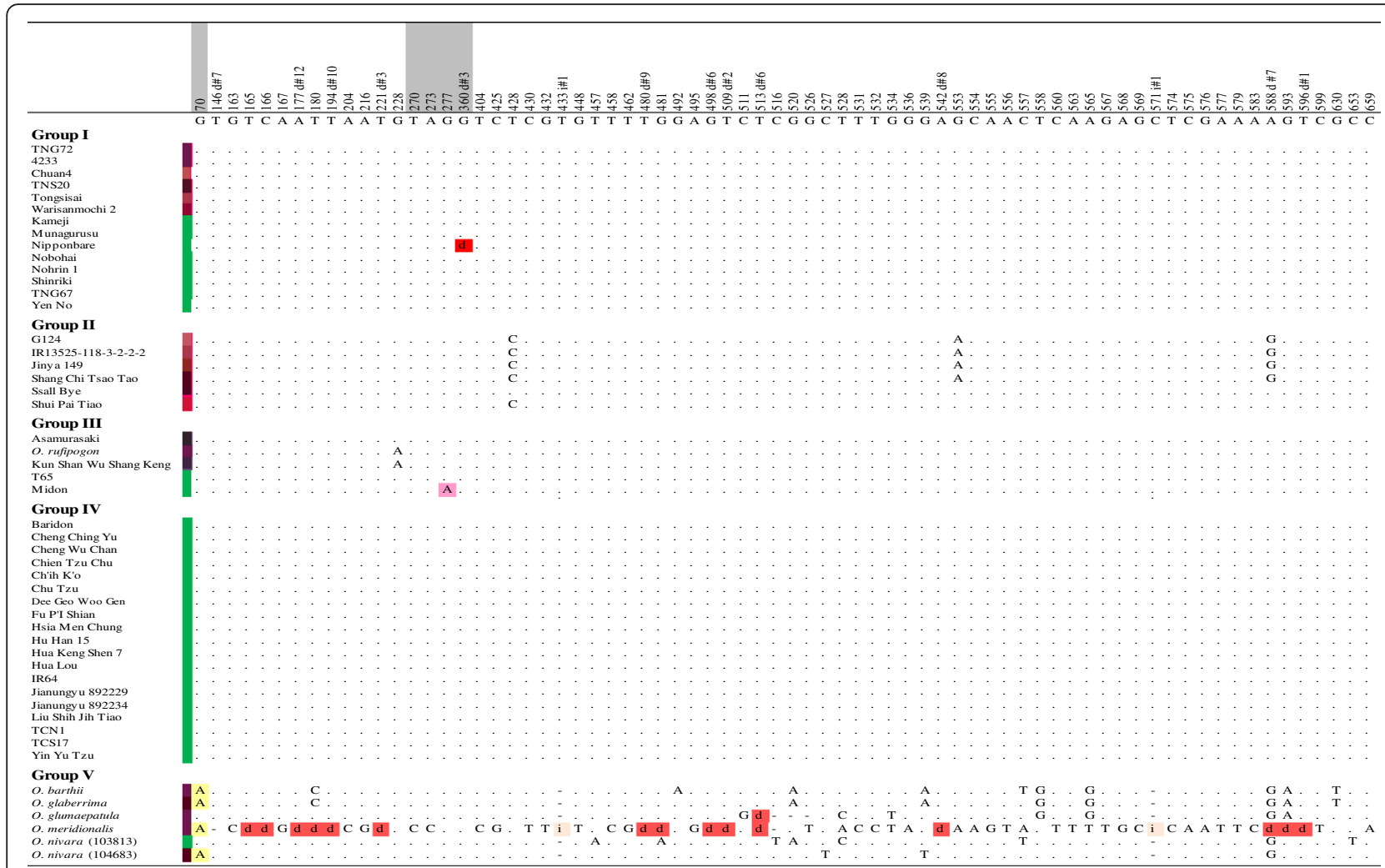

Fig. 4 Sequence variation of OsC1 in 50 accessions. According to DNA sequence variation, 5 groups were classified. The accessions of Group I exhibit red purple, purple, tryan rose and green leaf sheath and have complete OsC1 sequences closely resembling that of Tainung 72 . The accessions of Group II have red purple and tryan rose leaf sheath and share the sequence of Shang Chi Tsao Tao, which has one nonsynonymous mutation in position 1192. The accessions of Group III have blackish purple and green leaf sheath and share the sequence of Kun Shan Wu Siang Keng, which has one nonsynonymous mutation in position 918. The accessions of Group IV have green leaf sheath and share the sequence of Taichung Sen 17, which has a 10-bp deletion starting at position 796. The accessions of Group V include 6 wild A-genome species. Non-synonymous amino acid mutations were indicated to have similar function (yellow) or altered polarity (blue), charge (pink) and aromatic nature (green). d: deletion. i: insertion

Type 1) and KSWSK were embodied in one haplotype, H7. The indica cultivar TNS20 and the japonica cultivar Nipponbare had their own additional mutations and were separated into two distinct haplotypes, $\mathrm{H} 4$ and $\mathrm{H} 11$, respectively. The two accessions of $O$. nivara formed different haplotypes, $\mathrm{H} 12$ and $\mathrm{H} 13$, and were split from Cluster B1 because of diverse nucleotide sequences in both upstream and genic regions (Figs. 4 and 5).

\section{Discussion}

Allelic Diversity of OsC1 Responsible for Variation in Leaf Sheath Colors

Plants accumulate anthocyanin in various tissues as an aid to survival and reproduction. In rice, anthocyanin is deposited in the root, leaf sheath, internode, leaf blade, lemma, palea, apiculus, stigma, and pericarp. Tissuespecific anthocyanin accumulation is common in numerous genotypes. Purple pigmented traits in different tissues do not always co-segregate (Sakamoto et al. 2001). However, purple leaf sheath, apiculus, and stigma cosegregated in the
$\mathrm{F}_{2}$ population of PSH TNG72 $\times$ GSH TCS17 (Fig. 1) and other populations (Fan et al. 2008; Gao et al. 2011). Anthocyanin accumulation in the apiculus had previously been related to OsC1 (Takahashi 1957; Saitoh et al. 2004) but in the leaf sheath was thought to be inherited by polygenes or a single gene (Fig. 2; Fan et al. 2008; Wang et al. 2009; Gao et al. 2011).

OsC1, conferring leaf sheath color, was isolated from the $\mathrm{F}_{2}$ population of TNG72 $\times$ TCS17 by positional cloning (Fig. 2), differing from PSH1 (t) but the same as a locus identified from the somaclonal line Z418 (Wang et al. 2009; Gao et al. 2011). The PSH allele was dominant to GSH in crosses between natural germplasm or mutant lines. PSH TNG72 had a full length $O s C 1$ allele encoding 272 amino acids while GSH TCS17 had a 10bp deletion in the R3 Myb domain in exon 3, resulting in truncated translations of 207 amino acids. GSH cultivar Nipponbare had another mutated allele, a 3-bp deletion in the R3 Myb domain in exon 2 (Fig. 2). Among the 50 accessions analyzed herein, the 10-bp deletion was found in 17 indica landraces and improved cultivars 


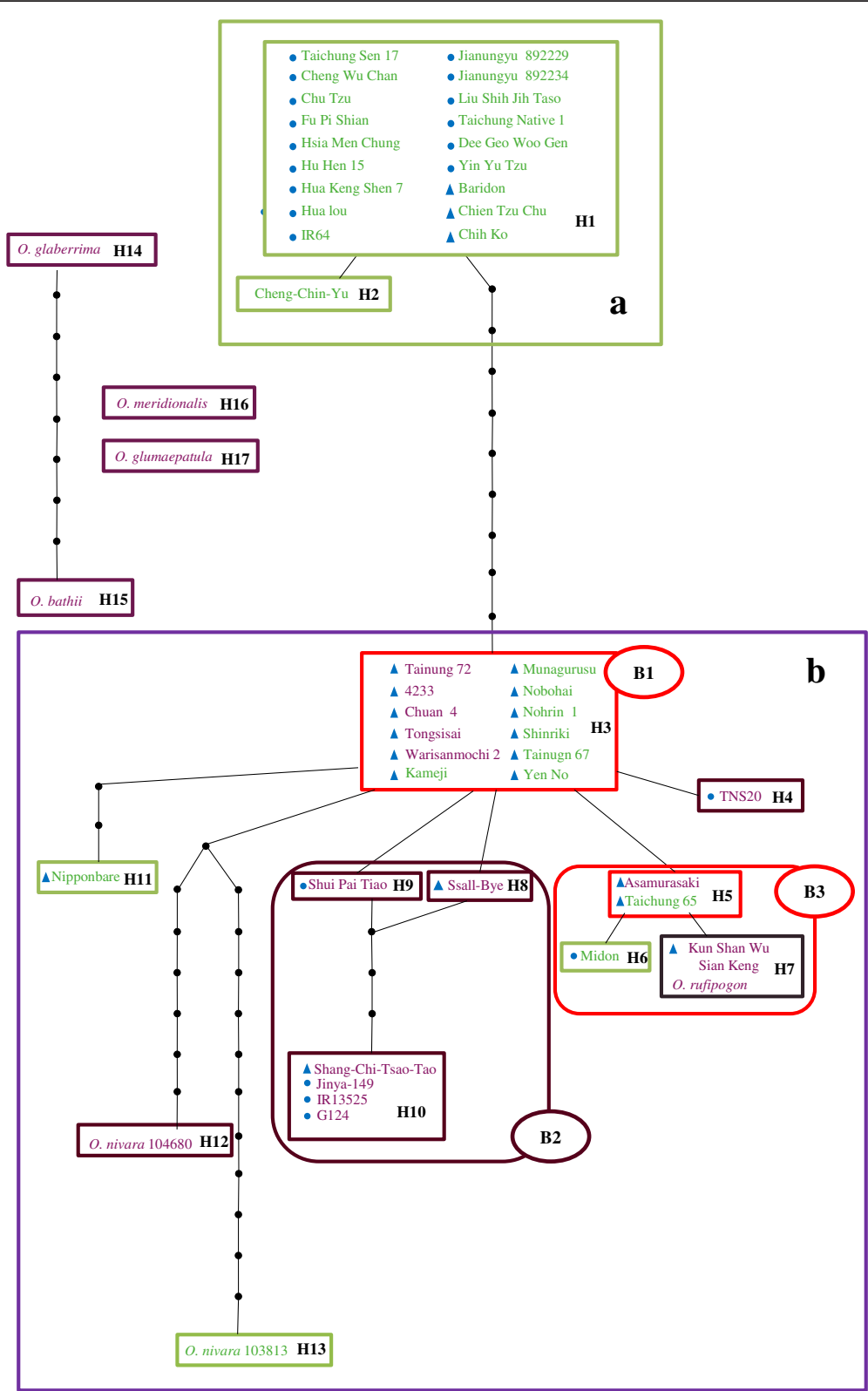

Fig. 5 Haplotype network analysis for OsC1. A total of 17 haplotypes, $\mathrm{H} 1-\mathrm{H} 17$, were discerned, and each is represented by a rectangle. In Asian rice, two major groups, Group a and Group b, are classified. Group b can be subdivided into three clusters, B1, B2, and B3, indicated by ovals. Blue dots and triangles indicate indica and japonica accessions, respectively. Text color resembles the color of leaf sheath (green, purple). Box line color resembles the color of leaf sheath of majority of accessions, green, pansy purple, red purple, and blackish purple, respective, besides red resembles admixture of different colors. Black nodes represent inferred branch on which each single nucleotide polymorphism occurred

from Taiwan, China, and the Philippines, and 2 japonica landraces from Taiwan (Fig. 4). The 10-bp deletion was conserved in 17 indigenous varieties in Northeast India and only observed in indica varieties from Taiwan, China, India, and Indonesia (Saitoh et al. 2004; Choudhury et al. 2014).

Ten GSH accessions without the 10-bp deletion of OsC1 had other mutated alleles or genes, leading to absence of anthocyanin pigmentation. Deletions of 3-bp in exon 2 and 2-bp in exon 3, both in the R3 Myb domain, were found in japonica rice from Japan and China, respectively (Figs. 2 and 4; Saitoh et al. 2004). Two GSH accessions, Midon and T65, had an amino acid substitution at position 918. However, three other accessions with the same substitution, Asamurasaki, KSWSK, and O. rufipogon, had blackish purple leaf sheath. Thus, mutations in genes other than $\mathrm{OsC1}$ were suggested to also eliminate anthocyanin pigmentation, a hypothesis 
Table 2 Nucleotide divergence of OsC1

\begin{tabular}{|c|c|c|c|c|c|c|c|c|}
\hline Taxon & $\mathrm{N}$ & $\mathrm{H}$ & $H_{d}$ & $\mathrm{~S}$ & $\pi_{T}$ & $\theta_{\mathrm{T}}$ & $\pi_{\text {sil }}$ & $\theta_{\text {sil }}$ \\
\hline O. sativa & 43 & 10 & 0.481 & 11 & 0.00104 & 0.00196 & 0.00146 & 0.00206 \\
\hline spp. indica & 23 & 7 & 0.522 & 10 & 0.00129 & 0.00208 & 0.00163 & 0.00201 \\
\hline purple leaf sheath & 5 & 4 & 0.900 & 7 & 0.00275 & 0.00257 & 0.00325 & 0.00284 \\
\hline green leaf sheath & 18 & 3 & 0.216 & 3 & 0.00026 & 0.00067 & 0.00016 & 0.00043 \\
\hline spp. japonica & 20 & 5 & 0.442 & 7 & 0.00074 & 0.00152 & 0.00127 & 0.00251 \\
\hline purple leaf sheath & 9 & 5 & 0.722 & 7 & 0.00144 & 0.00196 & 0.00246 & 0.00326 \\
\hline green leaf sheath & 11 & 2 & 0.182 & 1 & 0.00014 & 0.00026 & 0.00027 & 0.00051 \\
\hline Total numbers of purple leaf sheath & 14 & 8 & 0.857 & 9 & 0.00229 & 0.00216 & 0.00336 & 0.00279 \\
\hline Total numbers of green leaf sheath & 29 & 4 & 0.200 & 3 & 0.00021 & 0.00059 & 0.00020 & 0.00038 \\
\hline A-genome wild rice & 7 & 7 & 1.000 & 94 & 0.02584 & 0.03478 & 0.03568 & N.A. \\
\hline A-genome wild rice without $\mathrm{O}$. meridonalis & 6 & 6 & 1.000 & 37 & 0.01283 & 0.01325 & 0.01544 & 0.01612 \\
\hline
\end{tabular}

$N$ total number of sequences, $H$ total number of haplotypes at individual loci in each taxon, $H_{d}$ haplotype diversity, $S$ total number of polymorphic sites, $\pi_{T}$ average number of pairwise nucleotide difference per site calculated based on the total number of polymorphic sites, $\theta_{T}$ Watterson's estimator of $\theta$ per base pair calculated based on the total number of polymorphic sites, $\pi_{\text {sil }}$ average number of pairwise nucleotide difference per site calculated based on silent sites, $\theta_{\text {sil }}$ Watterson's estimator of $\theta$ per base pair calculated based on silent sites, N.A. Not applicable. When the proportion of differences is higher than 0.75 , the Jukes and Cantor correction cannot be computed

that was supported by seven japonica accessions having the same OsC1 coding sequence as PSH TNG72 (Fig. 4). OsC1, containing an R2R3 Myb domain, is thought to function as a transcription factor, regulating other genes involved in anthocyanin synthesis and enhancing another transcription factor, bHLH, regulating anthocyanin structural gene DFR (Dooner et al. 1991; Ithal and Reddy 2004). Failure of anthocyanin synthesis could result from malfunction of $\mathrm{OsC1}$ or any downstream proteins: for example, PSH1 (t) conferring purple leaf sheath was mapped on chromosome 1 (Wang et al. 2009). One of two activator genes, OsB1 and OsB2 encoding basic helix-loop-helix (bHLH) transcription factors, incorporated with maize $C 1$ could induce anthocyanin synthesis in the aleurone layer; however, the lack of function of these two genes in T65 resulted in green leaf blade and leaf sheath (Sakamoto et al. 2001). One japonica GSH accession, TNG67 which is a descendant of T65, had significantly reduced expression of $\mathrm{OsC1}$ despite having a full length amino acid encoding sequence (Fig. 3), suggesting feedback regulation of gene expression.

Fourteen PSH accessions exhibited variation in intensity of purple coloring of the leaf sheath, classified as tyran rose, pansy purple, red purple, and blackish purple. The anthocyanin contents of these 14 PSH accessions differed significantly (Fig. 3). However, OsC1 gene expression among three accessions with diverse anthocyanin contents, TNG72, SCTT, and KSWSK, showed only slight and non-significant differences. These three accessions represented three different haplotypes, H3, H7, and $\mathrm{H} 10$, respectively (Fig. 5). Allelic variation of $\mathrm{OsC1}$ accounted for anthocyanin accumulation and pigmentation in the leaf sheath, for which nonsynonymous mutations at the $\mathrm{C}$-terminal domain were found herein.

Table 3 Neutrality tests of OsC1

\begin{tabular}{|c|c|c|c|c|}
\hline Taxon & $\mathrm{N}$ & Tajima's D & Fu and Li's D & Fu and Li's F \\
\hline O. sativa & 43 & -1.41027 & -1.32676 & -1.59411 \\
\hline spp. indica & 23 & -1.27639 & -1.07742 & -1.32111 \\
\hline purple leaf sheath & 5 & 0.49788 & 0.49788 & 0.51896 \\
\hline green leaf sheath & 18 & $-1.71304^{*}$ & $-2.30153^{*}$ & $-2.45793^{*}$ \\
\hline spp. japonica & 20 & $-1.69169^{*}$ & -1.82926 & -2.06967 \\
\hline purple leaf sheath & 9 & -1.18930 & -1.02031 & -1.18277 \\
\hline green leaf sheath & 11 & -1.12850 & -1.28946 & -1.39919 \\
\hline Total number of purple leaf sheath & 14 & 0.23043 & 0.02189 & 0.08865 \\
\hline Total number of green leaf sheath & 29 & -1.53343 & -1.45773 & -1.71236 \\
\hline A-genome wild rice & 7 & -1.33215 & -1.32405 & -1.46956 \\
\hline A-genome wild rice without $\mathrm{O}$. meridonalis & 6 & -0.22043 & -0.17585 & -0.20295 \\
\hline
\end{tabular}

"The values of Tajima's D test and Fu and Li's D\&F test are at significance levels of $0.10<P<0.05$ 
The $\mathrm{C}$ terminus of R2R3 Myb transcription factors is an activation and repression domain (Dubos et al. 2010). Allelic variation of $\mathrm{OsC1}$ and Purple leaf $(\mathrm{Pl})$ coding regions also caused diverse intensities of purple apiculus pigmentation (Sakamoto et al. 2001; Saitoh et al. 2004). Allelic variation resulting in diversified phenotypes is very common, as exemplified by the great impact of different alleles of $W x$ and starch synthesis related genes on rice grain appearance, cooking and eating quality (Tian et al. 2009; Zhang et al. 2012; Wu et al. 2015). However, other genes participating in anthocyanin synthesis and environmental effects cannot be neglected (Sakamoto et al. 2001). Anthocyanin accumulation is frequently responsive to abiotic stresses, such as UVB radiation, temperature, and soil acidity (Reddy et al. 2004). A cis-element related to light regulation (-10PEHVPSBD, Thum et al. 2001) was found in the promoter region of OsC1 in TNG72 by using the PLACE database (https:// sogo.dna.affrc.go.jp/, Higo et al 1999). We noted that the leaf sheath accumulated more anthocyanin when rice plants were grown in soil under natural light than in hypotonic solution in the growth chamber.

\section{The Selection and Genealogy of OsC1}

Traits considered part of domestication syndromes are favored by artificial selection during domestication, and consequently distinguish cultivated plants from their wild progenitors. During domestication, genetic diversity of whole genomes can be dramatically reduced because of the 'genetic bottleneck' effect of selecting a few individuals as a founder population. The genetic diversities of genes contributing to domestication syndromes and improvement traits are often accompanied by artificial selection for production and culture, and the geographic distribution of alleles might be altered by human migration (Kovach et al., 2007; Kovach and McCouch 2008; Olsen and Wendel 2013). In rice, OsC1 conferring purple leaf sheath, apiculus, and stigma has been suggested as a domestication gene (Choudhury et al. 2014). Wild types are generally purple while cultivars tend to be green, although exceptions exist as noted above. The nucleotide diversity of $\mathrm{OsC1}$ was higher in O. rufipogon than in O. sativa, and $\mathrm{OsCl}$ of the haplotype of Asian cultivated accessions showed evidence of selection (Saitoh et al. 2004). In addition to perennial O. rufipogon and annual $O$. rufipogon (also called O. nivara), OsC1 sequences of 4 other wild species, O. glaberrima, O. barthii, $O$. glumaepatula, and O. meridionalis which had not been previously reported were subjected to allelic variation analysis. Sequence variation existed both in noncoding and coding regions. While these species had PSH, a few nonsynonymous amino acid substitutions were detected (Fig. 4). O. meridionalis (from Australia) had extremely divergent OsC1 DNA sequence, forming a distinct haplotype by itself, and all parameters regarding nucleotide divergence of $\mathrm{OsC1}$ decreased when it was not included in analysis (Table 2). African cultivated species, O. glaberrima, its progenitor $O$. barthii, and South American species, $O$. glumaepatula, also had their own specific sequences and formed 2 different haplotypes (Figs. 4 and 5). On the other hand, $O s C 1$ in Asian rice shared sequence similarity and formed 13 interconnected haplotypes. Allelic variation of $\mathrm{OsC1}$ in Asian, African, South American, and Australian rice reflected independent mutation without gene flow because of their geographic distribution. Two accessions of $O$. nivara and one accession of $O$. rufipogon together with 24 accessions of $O$. sativa were in Group B. The genealogy of OsC1 in the collected Asian rice accessions herein and other studies showed no distinct correlation with geographic distribution. The 10-bp deletion conferring GSH was prevalent in indica landraces and improved cultivars and rare in japonica accessions from many countries (Saitoh et al. 2004; Choudhury et al. 2014). The accessions in haplotypes $\mathrm{H} 3$ and $\mathrm{H} 10$ were collected from several countries (Fig. 5). Gene flow due to human activities might be an important factor in the geographic distribution of $\mathrm{OsC} 1$ alleles.

Purple leaf sheath, stigma, and apiculus are widespread in wild forms and often found in landraces, while green leaf sheath as well as colorless stigma and apiculus are common in modern cultivars. OsC1 nucleotide divergence was up to $90 \%$ lower in GSH than PSH although twice as many GSH accessions were studied (Table 2). However, no values from three neutral tests, Tajima's D, $\mathrm{Fu}$ and Li's D \& F, were significantly differently from neutral expectations, indicating that $\mathrm{OsC1}$ had not been subjected to selection-a conclusion that is supported by findings regarding $\mathrm{OsCl}$ in indigenous rice varieties in Northeast India (Choudhury et al. 2014). Genetic diversity was higher in indica than japonica accessions both in 14 $\mathrm{PSH}$ and $20 \mathrm{GSH}$ accessions, revealed by parameters reflecting nucleotide segregation at total polymorphic sites and silent sites, $\pi_{\mathrm{T}}, \theta_{\mathrm{T}}, \pi_{\text {sil }}$, and $\theta_{\text {sil }}$ (Table 2, Fig. 4). This phenomenon is congruent with evidence that genetic diversity is larger in subspecies indica than japonica (Garris et al. 2005).

Selection might not be a driving force for reducing genetic diversity in GSH. There is no significant evidence that $\mathrm{OsC1}$ deviated from neutral expectations in indica PSH or japonica PSH and GSH accessions. Nevertheless, indica GSH accessions might be experiencing relaxed purifying selection, indicated by neutrality tests at significance levels of $0.10<P<0.05$ (Table 3). Unlike other domestication syndromes directly related to productivity and other desirable traits that were selected for particular purposes over several thousand years, GSH might have been selected unintentionally. 
The Asian cultivated species, O. sativa, evolved from Asian wild rice progenitors $O$. nivara (annual) and $O$. rufipogon (perennial). O. sativa was domesticated from divergent wild populations about 10,000 years ago and diversified into two major subspecies, indica and japonica, subsequently being subjected to a long period of natural and artificial diversifying selection (Gross and Zhao 2014). Indica and japonica subspecies are distinguishable in morphology and physiology, already recognized as Hsien (long grain) and Keng (short grain) in the Han dynasty, China, over 2,000 years ago (Oka 1988; Callaway 2014). Numerous genes related to differentiation between these two subspecies experienced mutation and diversifying selection, e.g., Phr1 responsible for phenol reaction; and GS3, qSW5 and GS5 responsible for grain shape (Yu et al. 2008; Lu et al. 2013). The 10bp deletion conferring GSH was prevalent in indica landraces and improved cultivars and rare in japonica, but not in its progenitor species. The $\mathrm{OsCl}$ allele with 10-bp deletion was suggested to have originated and been an early target of domestication in subspecies indica (Figs. 4 and 5; Saitoh et al. 2004; Choudhury et al. 2014). In addition, 3-bp and 2-bp deletions in exon 2 and exon 3 of the R3 Myb domain were found in japonica rice from Japan and China, respectively. These two alleles were independent from the gene lineage of indica, which suggested mutation after subspecies divergence (Figs. 2 and 4; Saitoh et al. 2004).

Although reproductive barriers such as hybrid sterility and hybrid breakdown impede gene flow between cultivated rice and its wild progenitors, numerous interspecific crosses and successful introgressive hybridizations have been performed to unravel useful alleles and genes of wild species. Gene flow confounded with selection has been revealed at the genome level (Zhao et al. 2010; He et al. 2011; Yang et al. 2011) and in domesticationrelated genes including $W x, G S 3, S D 1$, and $q S H 1$ (Yamanaka et al. 2004; Konishi et al. 2006; Takano-Kai et al. 2009; Asano et al. 2011).

The genealogy of $\mathrm{OsC} 1$ suggests some gene flow events. O. rufipogon (Taiwan type 1) had an OsC1 sequence identical to that of Taiwan landrace KSWSK. One SNP aligned to japonica Asamursaki and Taichung 65 and indica Midon, accessions that were clustered in Group III and haplotype B3 (Fig. 4 and 5). Two O. nivara accessions also shared similar sequences to most japonica accessions and were classified as haplotype B1. Thus, $\mathrm{OsC1}$ in three Asian wild accessions closely resembled that of japonica but not indica, a finding which might support the hypothesis that japonica and indica were domesticated independently from O. rufipogon (Yang et al. 2011; Wei et al. 2014). Gene flow between subspecies was not rare, as revealed by genealogy of $\mathrm{OsC1}$ in 23 indica and 20 japonica accessions. In haplotype H1, three japonica landraces from Taiwan also possessed the 10-bp deletion specific to indica; in haplotype H10, one japonica landrace (Shang Chi Tsao Tao) and three indica accessions (Taiwan landrace Jinya-149, India landrace G124 and improved line IR1535) had the same allele (Figs. 4 and 5).

The genealogy of $\mathrm{OsC1}$ might not be in agreement with rice phylogeography because of human behavior. In Taiwan, $O$. rufipogon and $O$. nivara were once found in several swamp sites (Chang 1976) but, unfortunately, all habitats were destroyed several decades ago. Archaeological evidence shows that tropical japonica or indica had been cultivated over 5,000 years by ancient indigenous peoples in Taiwan (Hsieh et al. 2011). In the early 17th century, numerous Chinese migrated and carried many landraces (mostly indica) from coastal regions of Fujian and Guangdong Provinces of China to Taiwan. By the early 20th century, 1,197 indica accessions were identified officially in Taiwan, and 1,256 japonica accessions were introduced from Japan (Iso 1964). More than 1,000 of these accessions were deposited in The T.T. Chang Genetic Resources Center at the International Rice Research Institute (IRRI), the Philippines. Taiwanese rice germplasm was thus an admixture of indigenous wild species, landraces, and introduced germplasm from China and Japan; and was subsequently spread over Southeast Asia via the germplasm deposited in IRRI. As a result, introgression of $\mathrm{OsC1}$ may have occurred by hybridization between subspecies and both artificial and natural selection, clouding the true genealogy of OsC1.

\section{Conclusion}

We used positional cloning to isolate a PSH gene, revealing independent 10-and 3-bp deletions in the R2R3 $\mathrm{Myb}$ domain of $\mathrm{OsC1}$ that occurred in different lineages. Allelic diversity resulted in different $\mathrm{OsC1}$ protein function rather than gene expression levels, accounting for various degrees of anthocyanin accumulation and associated intensities of purple color. Allelic variation of $\mathrm{OsC1}$ among wild species, landraces, and cultivars revealed greatly reduced genetic variation in GSH phenotypes, but there was little evidence that $\mathrm{OsC1}$ had experienced recent selection, suggesting that it may have been enriched in cultivated forms by chance. Introgressions of OsC1 between subspecies indica and japonica were frequent through natural and artificial hybridization. Because of admixture of rice germplasm by artificial and natural selection in Taiwan, the genealogy of $\mathrm{OsC1}$ might not be accurately reflected by the current distribution of alleles through lineage diversification.

\section{Materials and methods Plant Materials}

Tainung 72 (TNG72), registered by Taiwan Agriculture Research Institute in 1987, is known as an aromatic elite 
cultivar. Taichung Sen 17 (TCS17), registered by Taichung District Agricultural Research and Extension Station in 1984, is one of two leading indica varieties in Taiwan. An $\mathrm{F}_{2}$ population of 624 individuals from a cross between these genotypes was planted in a paddy field at the Chiayi Agricultural Experiment Station (CAES), Taiwan, on January 21, 2008. The ratio of purple to green leaf sheath in the $F_{2}$ population was 2.92: 1 (465:159), indicating single gene inheritance with green sheath being recessive. The $159 \mathrm{~F}_{2}$ individuals possessing GSH, which were predicted to be recessive homozygotes, were subjected to linkage analysis.

A panel of 50 accessions obtained from the National Plant Genetic Resources Center (NPGRC), Taiwan and The Oryza Map Alignment Project (OMAP) were used to reveal DNA sequence diversity of the gene conferring leaf sheath color. As detailed in Table 1, the panel included: (a) 43 accessions of Asian cultivated rice, comprised of 21 ssp. japonica accessions (8 cultivars, 13 landraces) and 22 ssp. indica accessions (9 cultivars, 13 landraces), and (b) 7 accessions of A-genome wild rice, including O. rufipogon (Taiwan type 1), O. glaberrima (96717), O. barthii (10412), O. glumaepatula (105668), O. meridionalis (105300), and O. nivara (2 accessions: 103813, 104680). Geographically, 26 accessions were from Taiwan (12 indica, 13 japonica, 1 O. rufipogon), 11 from China (7 indica, 3 japonica, 1 O. nivara), 5 from Japan (5 japonica), 2 from the Philippines ( 2 indica), 2 from India (1 indica, 1 O. nivara), and 1 each from Australia (O. meridionalis); Cameroon (O. barthii); Brazil (O. glumaepatula) and Senegal (O. glaberrima). Regarding leaf sheath color, 20 and 30 accessions exhibited purple and green, respectively.

\section{Measurement of Anthocyanin Contents}

Total anthocyanin contents of leaf sheath and leaf blade harvested at four-leaf seedling and active tillering stages were quantified as described by Padmavati et al. (1997). Briefly, $0.5 \mathrm{~g}$ of fresh tissue was homogenized with extraction buffer and $1 \% \mathrm{HCl} /$ Methanol (V/V), for $24 \mathrm{~h}$ at $4{ }^{\circ} \mathrm{C}$ with occasional shaking. The supernatant was saved after centrifugation at $10,000 \mathrm{rpm}$ for $15 \mathrm{~min}$ at $4{ }^{\circ} \mathrm{C}$ and absorbance at $530 \mathrm{~nm}$ measured using a spectrophotometer (Metertech SP8001, Taiwan). The relative contents of anthocyanin were estimated from $\mathrm{A}_{530}$ using an $\mathrm{mM}$ extinction coefficient of 31.6 (Padmavati et al. 1997).

\section{Genetic and Physical Mapping of the Gene Conferring Purple Sheath}

For linkage analysis, 159 GSH $\mathrm{F}_{2}$ progeny, predicted to be recessive homozygotes, were genotyped with 121 polymorphic markers, including 67 SSR and 54 indel markers distributed over the 12 rice chromosomes. SSR primer sequences were retrieved from Gramene (http:// www.gramene.org). The 54 indel markers were newly designed based on sequence divergence between Nipponbare (japonica) and 93-11 (indica) (Additional file 1: Table S1). DNA extraction and genotype assays of PCRbased markers was as described (Hsu et al. 2014). The linkage map was constructed with a LOD threshold of 3.5 by using MapMaker Exp 3.0 (Lander et al. 1987). The physical map of the target interval containing candidate genes was retrieved from the Rice Genome Annotation Project (RGAP, http://rice.plantbiology.msu.edu).

\section{Gene Expression of $\mathrm{OsC1}$}

Four accessions displaying various degrees of PSH were subjected to quantitative real-time PCR (qPCR) to investigate the relationship of $\mathrm{OsC1}$ gene expression with anthocyanin contents. These four accessions were japonica rice, Tainung 67 (TNG67, green), Tainung 72 (TNG72, light purple), Shang Chi Tsao Tao (SCTT, purple), and Kun Shan Wu Siang Keng (KSWSK, dark purple). Total RNA was extracted by using TRIZOL (Invitrogen, USA), and contaminating DNA was removed by using a TURBO DNA-free kit (Ambion, USA), according to manufacturer's protocols. Primers of $\mathrm{OsC1}$ cDNA for qPCR were designed based on the gene sequence of GenBank accession number Y15219, and were forward primer: $5{ }^{\prime}$-CAACgAg CTggTTTgAggCggT-3' and reverse primer: 5'-TgAgA gACCACCTgTTgCCgAg-3'. Quantitation of gene expression and calculation of relative gene expression were as described (Hsu et al. 2014).

\section{Genetic Diversity Assessment}

A panel of 50 accessions (above) possessing a range of leaf sheath colors were used to assess genetic diversity of OsC1. The OsC1 DNA sequences of 1,311 bp were amplified by use of KOD plus Taq polymerase (TOYOBO, Japan) and Kapa Hifi DNA polymerase with three sets of primers, set 1 (F: 5'-ACATCgTACggggCTACAAg-3', R: 5'-AgCgTTAgCCAgCTTCAAAT-3'), set 2 (F: 5'-ACTAT CTCCggCCTAACATCAA-3'， R: 5'-TAgTAgTCgCAg TCgACgTC-3'), and set 3 (F: 5'-ATgTTgTCAggT ggTCTCTC-3', R: 5'-CACgTT CATgCAACCTTTTg-3'). The amplicons were sequenced using an ABI3730 DNA Analyzer following manufacturer's protocol. The sequences were assembled and then subjected to multiple alignments using DNAMAN ver. 6.0 (Lynnon Biosoft) and consequently MAGA ver. 6.0 (Tamura et al. 2013).

Genetic divergence of the OsC1 gene region was estimated with $\pi$ (average nucleotide diversity per site, Nei and $\mathrm{Li}$ 1979) and $\theta_{\mathrm{w}}$ (number of segregating sites, Watterson 1975) according to DnaSP version 5.10.1 (Librado and Rozas 2009). Two neutrality tests, 1) Tajima's D and 2) Fu and Li's $D^{*} \& \mathrm{~F}^{*}$, were conducted to investigate whether there was any deviation from neutrality by using DnaSP version 5.10.1. Tajima's D estimates the difference between the mean pairwise differences $(\pi)$ and Watterson's estimator 
$\left(\theta_{\mathrm{w}}\right)$ (Tajima 1989). Fu and Li's $\mathrm{D}^{*} \& \mathrm{~F}^{*}$ test reveals the discrepancy between the number of polymorphic sites in external and internal groups (Fu and $\mathrm{Li}$ 1993). A haplotype network, based on the probability of parsimony and calculated for pairwise differences until it exceeds 0.95 , was constructed using TCS1.21 (Templeton et al. 1992).

\section{Additional file}

Additional file 1: Table S1. Newly designed markers used in coarse mapping. (DOCX $17 \mathrm{~kb}$ )

\section{Competing Interests}

The authors declare that they have no competing interests.

\section{Authors' Contributions}

YW and YL designed and supervised the research; YW conducted the genetic materials and field trials; $\mathrm{HC}$, and $\mathrm{CH}$ performed the experiments; $\mathrm{HC}, \mathrm{AH}$ and $\mathrm{YL}$ analyzed the data. $\mathrm{HC}, \mathrm{AH}$, and $\mathrm{YL}$ wrote the manuscript. All authors read and approved the final manuscript.

\section{Acknowledgments}

This work was supported by the National Science Council (NSC 100-2313B-002-055, NSC 101-2313-B-002-005) of Taiwan. The authors are thankful to Drs. Yue-ie C. Hsing and Yuan-chin Tsai for providing leaf tissue of wild rice species and Su-chen Kuo for field management. We also appreciate the services of Professor Hawkeye, LLC for critical review and English editing.

\section{Author details}

${ }^{1}$ Department of Agronomy, National Taiwan University, Taipei, Taiwan. ${ }^{2}$ Department of Agronomy, Chiayi Agricultural Experiment Station, Taiwan Agricultural Research Institute, Chiayi, Taiwan. ${ }^{3}$ Department of Life Science, Fu-Jen Catholic University, Xinbei, Taiwan. ${ }^{4}$ Department of Agricultural Chemistry, National Taiwan University, Taipei, Taiwan.

Received: 13 November 2015 Accepted: 19 February 2016 Published online: 27 February 2016

\section{References}

Asano K, Yamasaki M, Takuno S, Miura K, Katagiri S, Ito T, et al (2011) Artificial selection for a green revolution gene during japonica rice domestication. Proc Natl Acad Sci USA 108:11034-11039

Asano K, Takashi T, Miura K, Qian Q, Kitano H, Matsuoka M et al (2007) Genetic and molecular analysis of utility of sd1 alleles in rice breeding. Breeding Sci 57:53-58

Brenda WS (2001) Flavonoid biosynthesis. A colorful model for genetics, biochemistry, cell biology, and biotechnology. Plant Physiol 126:485-493 Callaway E (2014) Domestication: the birth of rice. Nature 514:S58-S59

Chandler VL, Radicella JP, Robbins TP, Chen J, Turks D (1989) Two regulatory genes of the maize anthocyanin pathway are homologous: isolation of $B$ utilizing $R$ genomic sequences. Plant Cell 1:175-183

Chang TT (1976) The origin, evolution, cultivation, dissemination, and diversification of Asian and African rices. Euphytica 25:425-441

Chalker-Scott L (1999) Environmental significance of anthocyanins in plant stress responses. Photochem Photobiol 70:1-9

Choudhury Bl, Khan ML, Dayanandan S (2014) Patterns of nucleotide diversity and phenotypes of two domestication related gene (OsC1 and $W x)$ in indigenous rice varieties in northeast India. BMC Genet 15:71-82

Dooner HK, Robbins TP, Jorgensen RA (1991) Genetics and development control of anthocyanin biosynthesis. Annu Rev Genet 25:173-199

Dubos C, Stracke R, Grotewold E, Weisshaar B, Martin C, Lepiniec L (2010) MYB transcription factors in Arabidopsis. Trends Plant Sci 15:573-581

Fan FJ, Fan YY, Du JH, Zhuang JY (2008) Fine mapping of C (Chromogen of anthocyanin) gene in rice. Rice Sci 15:1-6

Fu YX, Li WH (1993) Statistical tests of neutrality mutations. Genetics 133:693-709

Gao D, He B, Zhou Y, Sun L (2011) Genetic and molecular analysis of a purple sheath somaclonal mutant in japonica rice. Mol Breeding 7:73-83
Gross BL, Zhao Z (2014) Archaeological and genetic insights into the origins of domesticated rice. Proc Natl Acad Sci U S A 111:6190-6197

Garris AJ, Tai TH, Coburn J, Kresovich S, McCouch S (2005) Genetic structure and diversity in Oryza sativa L. Genetics 169:1631-1638

Hadagal BN, Manjunath A, Goud JV (1980) Linkage of genes for anthocyanin pigmentation in rice (Oryza sativa L.). Euphytica 30:747-754

He Z, Zhai W, Wen H, Tang T, Wang Y, Lu X et al (2011) Two evolutionary histories in the genome of rice: the roles of domestication genes. PLoS Genet 7:e1002100

Higo K, Ugawa Y,Iwamoto M, Korenaga T. (1999) Plant cis-acting regulatory DNA elements (PLACE) database. Nucleic Acids Res. 27:297-300

Hsieh JS, Hsing YI, Hsu TF, Li JK, Li KT, Tsang CH (2011) Studies on ancient rice-where botanists, agronomists, archeologists, linguists, and ethnologists meet. Rice 4:178-183

Hsu YC, Tseng MC, Wu YP, Lin MY, Wei FJ, Hwu KK et al (2014) Genetic factors responsible for eating and cooking qualities of rice grains in a recombinant inbred population of an inter-subspecific cross. Mol Breeding 34:655-673

Iso E (1964) Talks on Horai rice. Amayomikai, Yamakuchi, Japan, p 89, in Japanese

Ithal N, Reddy AR (2004) Rice flavonoid pathway genes, OsDfr and OsAns, are induced by dehydration, high salt and $A B A$, and contain stress responsive promoter elements that interact with the transcription activator, OsC1-MYB. Plant Sci 166:1503-1513

Koes R, Verweij W, Quattrocchio F (2005) Flavonoids: a colorful model for the regulation and evolution of biochemical pathways. Trends Plant Sci 10:1360-1385

Konishi S, Izawa T, Lin SY, Ebana K, Fukuta Y, Sasaki T et al (2006) An SNP caused loss of seed shattering during rice domestication. Science 312:1392-1396

Kovach MJ, Calingacion MN, Fitzgerald MA, McCouch SR (2009) The origin and evolution of fragrance in rice. Proc Natl Acad Sci U S A 106:14444-14449

Kovach MJ, McCouch SR (2008) Leveraging natural diversity: back through the bottleneck. Curr Opin Plant Biol 11:193-200

Kovach MJ, Sweeney MT, McCouch SR (2007) New insights into the history of rice domestication. Trends Genet 23:578-587

Lander ES, Green P, Abrahamson J, Barlow A, Day MJ, Lincoln SE et al (1987) MapMarker: an interactive computer package for constructing primary genetic linkage maps of experimental and natural populations. Genomics 1:174-18

Librado P, Rozas J (2009) DnaSP v5: a software for comprehensive analysis of DNA polymorphism data. Bioinformatics 25:1451-1452

Larson G, Piperno DR, Allaby RG, Purugganan MD, Andersson L, Arroyo-Kalin M et al (2014) Current perspectives and the future of domestication studies. Proc Natl Acad Sci U S A 111:6139-6146

Lu L, Shao D, Qiu X, Sun L, Yan W, Zhou X et al (2013) Natural variation and artificial selection in four genes determine grain shape in rice. New Phytol 200:1269-1280

Nei M, Li WH (1979) Mathematical model for studying genetic variation in terms of restriction endonucleases. Proc Natl Acad Sci U S A 76:5269-5273

Oka HI (1988) Origin of cultivated rice. Japan Sci Soc Elsevier, Tokyo

Olsen KM, Purugganan MD (2002) Molecular evidence on the origin and evolution of glutinous rice. Genetics 162:941-950

Olsen KM, Wendel JF (2013) A bountiful harvest: genomic insights into crop domestication phenotypes. Annu Rev Plant Biol 64:47-70

Padmavati M, Sakthivel N, Tahara KV, Reddy AR (1997) Differential sensitivity of rice pathogens to growth inhibition by flavonoids. Phytochem 46:499-502

Reddy KR, Kakani VG, Zhao D, Koti S, Gao W (2004) Interactive effects of ultraviolet-B radiation and temperature on cotton physiology, growth, development and hyperspectral reflectance. Photochem Photobiol 79:416-427

Reddy VS, Dash S, Reddy AR (1995) Anthocyanin pathway in rice (Oryza sativa L): identification of a mutant showing dominant inhibition of anthocaynins in leaf and accumulation of proanthocaynidins in pericarp. Theor Appl Genet 91:301-312

Reddy VS, Goud KV, Sharma R, Reddy AR (1994) Ultraviolet-B-responsive anthocyanin production in a rice cultivar is associated with a specific phase of phenylalanine ammonia lyase biosynthesis. Plant Physiol 105:1059-1066

Reddy VS, Scheffler BE, Wienand U, Wessler SR, Reddy AR (1998) Cloning and characterization of the rice homologue of the maize C1 anthocyanin regulatory gene. Plant Mol Biol 36:497-498

Saitoh K, Onishi K, Mikami I, Thidar K, Sano Y (2004) Allelic diversification at the C (OsC1) locus of wild and cultivated rice: nucleotide changes associated with phenotypes. Genetics 168:997-1007

Sakamoto W, Ohmori T, Kageyama K, Miyazaki C, Saito A, Murata M, Noda K, Maekawa M (2001) The purple leaf (PI) locus of rice: the $P{ }^{\prime w}$ allele has a complex organization and includes two genes encoding basic helix-loophelix proteins involved in anthocyanin biosynthesis. Plant Cell Physiol 42:982-991 
Tajima F (1989) Statistical method for testing the neutral mutation hypothesis by DNA polymorphism. Genetics 123:585-595

Tamura K, Stecher G, Peterson D, Filipski A, Kumar S (2013) MEGA6: Molecular Evolutionary Genetics Analysis version 6.0. Mol Biol Evol 30:2725-2729

Takahashi ME (1957) Analysis on apiculus color genes essential to anthocyanin coloration rice. J Facu Agr Hokkaido Univ 50:266-362

Takano-Kai N, Jiang H, Kubo T, Sweeney M, Matsumoto T, Kanamori H et al (2009) Evolutionary history of GS3, a gene conferring grain length in rice. Genetics 182:1323-1334

Templeton AR, Crandall KA, Sing CF (1992) A cladistic analysis of phenotypic associations with haplotypes inferred from restriction endonuclease mapping and DNA sequence data. III Cladogram estimation. Genetics 132:619-633

Thum KE, Kim M, Morishige DT, Eibl C, Koop HU, Mullet JE (2001) Analysis of barley chloroplast $p s b D$ light-responsive promoter elements in transplastomic tobacco. Plant Mol Biol 47:353-366

Tian Z, Qian Q, Liu Q, Yan M, Liu X, Yan C et al (2009) Allelic diversities in rice starch biosynthesis lead to a diverse array of rice eating and cooking qualities, Proc Natl Acad Sci U. S A 106:21760-21765

Wang WY, Ding HF, Li GX, Jiang MS, Li RF, Liu X et al (2009) Delimitation of the $\mathrm{PSH}$ ( $\mathrm{t}$ ) gene for rice purple leaf sheath to $23.5 \mathrm{~kb}$ DNA fragment. Genome 52:268-274

Watterson GA (1975) On the number of segregating sites in genetic models without recombination. Theoret Pop Biol 7:256-276

Wei X, Qian W, Yuan N, Chen Y, Wang R, Cao L et al (2014) Domestication and association analysis of $\mathrm{Hd} 1$ in Chinese mini-core collections of rice. Genet Resour Crop Evol 61:121-142

Wu YP, Pu CH, Lin HY, Huang HY, Huang YC, Hong CY et al (2015) Three novel alleles of FLOURY ENDOSPERM2 (FLO2) conferring dull rice grains with low amylose content. Plant Sci 233:44-52

Yamanaka S, Nakamura I, Watanabe N, Sato YI (2004) Identification of SNPs in the waxy gene among glutinous rice cultivars and their evolutionary significance during the domestication process of rice. Theor Appl Genet 108:1200-1204

Yang CC, Kawahara Y, Mizuno H, Wu J, Matsumoto T, Itoh T (2011) Independent domestication of Asian rice followed by gene flow from japonica to indica. Mol Biol Evol 29:1471-1479

Yu Y, Tang T, Qian Q, Wang Y, Yan M, Zeng D et al (2008) Independent losses of function in a polyphenol oxidase in rice: differentiation in grain discoloration between subspecies and the role of positive selection under domestication. Plant Cell 20:2946-2959

Yue B, Cui KH, Yu SB, Xue WY, Luo L, Xing YZ (2006) Molecular marker-assisted dissection of quantitative trait loci for seven morphological traits in rice (Oryza sativa L.). Euphytica 150:131-139

Zhang LB, Zhu Q, Wu ZQ, Ross-lbarra J, Gaut BS, Ge S et al (2009) Selection on grain shattering genes and rates of rice domestication. New Phytol 184:708-720

Zhang Z, Li M, Fang Y, Liu F, Lu Y, Meng Q et al (2012) Diversification of the Waxy gene is closely related to variations in rice eating and cooking quality. Plant Mol Biol Rep 30:462-469

Zhao K, Wright M, Kimball J, Eizenga G, McClung A, Kovach M et al (2010) Genomic diversity and introgression in $O$. sativa reveal the impact of domestication and breeding on the rice genome. PLoS One 5, e10780

\section{Submit your manuscript to a SpringerOpen ${ }^{\circ}$ journal and benefit from:}

- Convenient online submission

- Rigorous peer review

- Immediate publication on acceptance

- Open access: articles freely available online

- High visibility within the field

- Retaining the copyright to your article

Submit your next manuscript at $\boldsymbol{s p r i n g e r o p e n . c o m ~}$ 